GANIT J. Bangladesh Math. Soc. (ISSN 1606-3694) 39 (2019) 27-43

DOI: https://doi.org/10.3329/ganit.v39i0.44164

\title{
NUMERICAL SIMULATION ON HEAT FLOW FOR MIXED CONVECTION WITHIN A TRIANGULAR ENCLOSURE
}

\author{
${ }^{1}$ Muhammad Sajjad Hossain, ${ }^{* 1}$ M.M. Billah, ${ }^{2}$ M. Z. I. Bangalee and ${ }^{3}$ M. A. Alim \\ ${ }^{1}$ Department of Arts and Sciences, Ahsanullah University of Science and Technology (AUST) \\ Dhaka-1208, Bangladesh \\ ${ }^{2}$ Department of Applied Mathematics, University of Dhaka, Dhaka-1000, Bangladesh \\ ${ }^{3}$ Department of Mathematics, Bangladesh University of Engineering and Technology (BUET) \\ Dhaka-1000, Bangladesh \\ *Corresponding author, Email: mmb.edu@ gmail.com
}

Received: 20-02-2019 Accepted : 11-11-2019

\begin{abstract}
Heat flow for laminar mixed convection in a triangular enclosure with uniformly heated bottom wall is solved using Galerkin weighted residual method of finite element formulation. A fluid with Prandtl number $(\mathrm{Pr}=0.71)$ is also used to investigate the effects of heat flow for Reynolds number $(40 \leq R e \leq 110)$ varying Rayleigh number $\left(10^{3} \leq R a \leq 10^{4}\right)$ in that enclosure. In the enclosure, the left wall is considered cold; bottom wall is uniformly heated while the other inclined wall is insulated. The geometry of physical problems is represented mathematically by different sets of governing equations along with appropriate boundary conditions. Results are shown in terms of streamlines, isotherms, average Nusselt number and average temperature of the fluid in the cavity for uniform heating of bottom wall. It is seen that heat transfer rate from the heat source is higher for increasing value of $R e$. On the other hand, average bulk temperature declines significantly. It is also indicated that for fixed Prandtl number and various Ra, the buoyancy force and heat transfer rate inside the enclosure are increased for the greater value of $R e$.
\end{abstract}

Keywords: Mixed convection, Triangular enclosure, Stream function, Isotherms, Galerkin weighted residual methodof finite element formulation

\section{Introduction}

Investigation of mixed convection generally induced in enclosed cavities or channels containing heating elements on one of its walls or on both walls is necessary from both practical and theoretical points of view. Most of the common enclosures, such as, rectangular, cylinder, trapezoidal and triangular are used in industries. Because of applicability of triangular enclosures in various fields it has received a considerable attention and the numerous studies related to mixed convection in enclosure cavity have been reported in order to investigate the heat transfer and fluid flow in such geometry.

(C) GANIT: Journal of Bangladesh Mathematical Society, 2019 
A numerical study on laminar natural convection with a variety of flow system in triangular cavity has been made by Akinsete and coleman [1]. The authors solved the problem for different aspect ratios and Grashof numbers and concluded that a considerable amount of the heat transfer across the base wall of the region took place near the connection of the base and the hypotenuse. Asan and Namli [2] investigated a pitched roof of triangular cross-section for summer day boundary conditions. They obtained steady state solutions on the flow structure and heat transfers for heightbase ratio and Rayleigh number. The natural convection phenomena in a right-angled triangular enclosure are studied numerically by Basak et al. [3]. They considered two cases. Firstly, vertical wall is uniformly or linearly heated while inclined wall is cold isothermal and secondly inclined wall is uniformly or linearly heated while vertical wall is cold isothermal whereas horizontal bottom wall is adiabatic and the aspect ratio of the lengths of base and height is considered to be one. They found that isotherms are almost parallel near the bottom portion of the triangular enclosure at low Rayleigh numbers $\left(R a \leq 10^{4}\right)$ and more distorted for $R a=10^{5}$ and shown that heat transfer rate, that is, the average Nusselt number for vertical wall is $\sqrt{ } 2$ times that of the inclined wall whereas the bottom wall is adiabatic and that verifies the thermal equilibrium of the system for all case studies.

Basak et al. [4] also analyzed heat recovery and thermal transport in materials confined within triangular cavity based on heat lines and heat lines is used to visualize the heat energy trajectory. In the meantime, Basak et al. [5] demonstrated natural convection and flow simulation with porous medium in differentially heated isosceles triangular enclosures. It is observed that heat transmits above all owe to conduction for different Pr due to small Darcy number. A change since conduction dominant system to convection dominant regime has been found for increasing value of Darcy number.In mixed convection, structures of laminar wakes and heat transfer in a horizontal channel with a built-in square cylinder were studied numerically by Biswas et al. [6]. In this study, it has been found that the channel walls and the surface of the bluff body have higher temperatures than the incoming flow and the mixed convection kick off periodicity and irregularity in the wake at a lower Re than forced convection alone.Role of numerous discrete warmers to find out lower entropy invention through natural convection in fluid filled square and triangular cavities was learnt by Das etal. [8].Das and Basak [9] also performed heated discretely porous square and triangular enclosures by natural convection. The pattern of heat flow inside the cavities for a variety of parameters is imagined by the heatline method. Heatlines show the position of hot system along the side walls and explain the variations of heat transfer rates as well as the local and average Nusselt numbers. This is also observed that the strength of heat flow is seemed to be higher for the asymmetric dispersed heating strategy than symmetric distributed heating patterns. Moreover, Hossain and Gorla [10] investigated viscous dissipation effects on unsteady combined convective heat transfer to water close to its density maximum in a rectangular cavity with isothermal wall. Karyakin and Sokovishin [11] presented convection patterns on isosceles triangular enclosure. After that Kaushik et al. [12] performed a triangular built-in-storage stellar water temperature. Besides, the steady viscous flow 
through efficient numerical techniques in a triangular cavity was studied by Li and Tang [13]. They established accurate and efficient calculations of the flow for high Ra numbers inside a triangular cavity and have been able to compute numerical solution for scalene triangular cavity problems. Side by side, two-dimensional flow containing a temperature gradient in a two-sided lid-driven cavity was inspected numerically by Luo and Yang [14].However, the numerical study to investigate the combined forced and natural convection cooling of heat dissipating electronic components located in rectangular enclosure and cooled by an external through flow of air carried out a series by Papanicolaou and Jaluria [16, 17]. Rahman et al. [18] carried out opposing mixed convection in a vented enclosure numerically. They observed that the convective heat transfer becomes the largest over the conduction heat transfer among the increase of Reynolds and Richardson numbers and the speed of heat up transfer from the heated wall is notably dependent on the place of the inlet port. The joined thermal boundary levels taking both sides partition placed in an isosceles triangular enclosure alongside its center symmetric line and considering air fluid were explored by Saha et.al [19]. Time dependent aspects of the joined thermal boundary layers as well as natural convection flow in the partitioned cavity judged against among the non-partitioned cavity and also heat transfer rates have been chattered here. Sheremet et al. [20] studied a right-angled wave based triangular enclosure on usual convection of micro-polar fluid. Flow reduction of fluid with the aid of vortex stickiness factor and heat up transfer fall has been analyzed in the obtained results. Varol et al. [21] considered steady-state free convection in porous media right-angle triangular enclosure. They showed the effect of aspect ratios for the range of 0.25 to 1.0 and investigated heat transfer and flow field for governing parameter Rayleigh numbers $50 \leq R a \leq 1000$.

To the best knowledge of the authors, no attention has been paid to the problem of heat flow for mixed convection in a lid driven triangular enclosure with uniform heating of bottom wall. The present work demonstrates the abovementioned issue.

\section{Mathematical Formulation of the Problem}

The physical model considered in the present study is a two-dimensional triangular enclosure as shown in Figure 1.

The length and height of the enclosures are depicted by $L$ and $H$, respectively. The temperature $\left(T_{h}\right)$ of the bottom wall is higher than the temperature $\left(T_{c}\right)$ of the vertical wall while the inclined walls are kept insulated. The vertical wall is assumed to slide from bottom to top at a constant speed $V_{0}$. The origin of the Cartesian coordinate system is placed at the left bottom corner of the enclosure. The gravity acts normal to $X$-axis. The fluid is Newtonian, and the fluid flow is considered to be laminar with Prandtl number $(\operatorname{Pr}=0.71)$. The properties of the fluid were assumed being constant. 


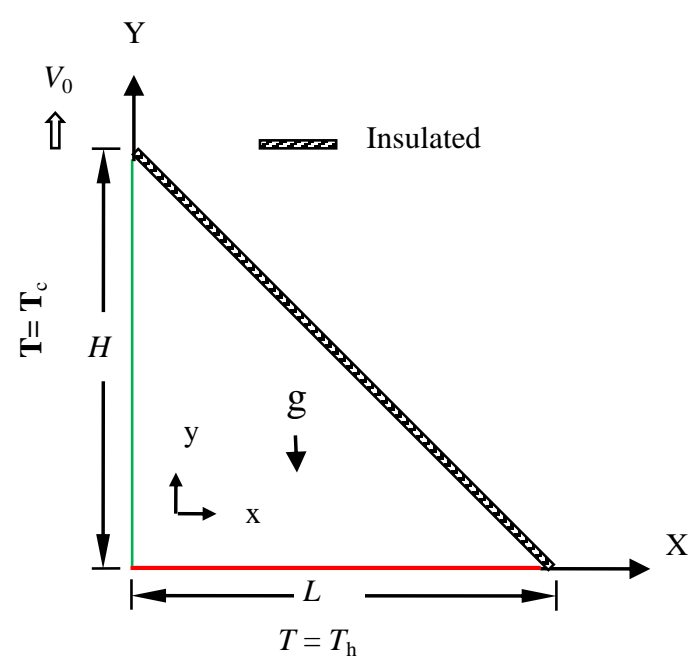

Fig. 1: Schematic of the physical domain with boundary conditions

In this Problem, under the usual Boussinesq approximation, the governing equations for the present problem can be described in dimensionless form as follows:

$$
\begin{aligned}
& \frac{\partial U}{\partial X}+\frac{\partial V}{\partial Y}=0 \\
& U \frac{\partial U}{\partial X}+V \frac{\partial U}{\partial Y}=-\frac{\partial P}{\partial X}+\frac{1}{\operatorname{Re}}\left(\frac{\partial^{2} U}{\partial X^{2}}+\frac{\partial^{2} U}{\partial Y^{2}}\right) \\
& U \frac{\partial V}{\partial X}+V \frac{\partial V}{\partial Y}=-\frac{\partial P}{\partial Y}+\frac{1}{R e}\left(\frac{\partial^{2} V}{\partial X^{2}}+\frac{\partial^{2} V}{\partial Y^{2}}\right)+R a \operatorname{Pr} \theta \\
& U \frac{\partial \theta}{\partial X}+V \frac{\partial \theta}{\partial Y}=\frac{1}{\operatorname{RePr}}\left(\frac{\partial^{2} \theta}{\partial X^{2}}+\frac{\partial^{2} \theta}{\partial Y^{2}}\right)
\end{aligned}
$$

where the dimensionless variables are,

$$
\begin{gathered}
X=\frac{x}{L}, \quad Y=\frac{y}{L}, \quad U=\frac{u}{V_{0}}, \quad V=\frac{v}{V_{0}}, \quad P=\frac{p}{\rho V_{0}^{2}}, \Delta T=T_{h}-T_{c}, \quad \alpha=\frac{\kappa}{\rho C_{p}}, \\
\theta=\frac{\left(T-T_{c}\right)}{\left(T_{h}-T_{c}\right)}, \quad \operatorname{Re}=\frac{V_{0} L}{v}, \quad \operatorname{Pr}=\frac{v}{\alpha}, G r=\frac{g \beta \Delta T L^{3}}{v^{2}}, R a=(G r)(\operatorname{Pr})
\end{gathered}
$$

The associated dimensionless boundary conditions used to solve equations (1)-(4) can be written as: At the bottom wall (Heated Uniformly): $U=0, V=0, \theta=1$

At the left vertical wall: $U=0, V=1, \theta=0$

At the inclined wall: $U=0, V=0, \frac{\partial \theta}{\partial N}=0$ 
Where, $N$ is the non-dimensional distances either along $X$ or $Y$ direction acting normal to the surface. The average Nusselt number at the heated wall of the enclosure based on the nondimensional variables may be expressed as $N u_{a v}=-\int_{0}^{1}\left(\frac{\partial \theta}{\partial Y}\right) d X$ and the bulk average temperature defined as $\theta_{a v}=\int \theta d \bar{V} / \bar{V}$, where $V$ is the enclosure volume.

\section{Numerical Method of Solution}

The non-dimensional governing momentum and energy balance partial differential equations together with the boundary conditions has been solved using numerical technique based on the Galerkin weighted residual method [7, 15].In particular the non-linear parametric solution method is chosen to solve the governing equations for its fast convergence benefit. A non-uniform triangular mesh arrangement has been implemented to capture the rapid changes in the dependent variables. The fundamental unknown elements for the governing partial differential equations are the velocity components $(U, V)$, the temperature $(\theta)$, and the pressure, $(P)$. The six node triangular element is applied to cope with the finite element equations. All six nodes are related with velocities along with temperature; but barely three corner nodes are attached among pressure. This means, a lower order polynomial is selected for pressure and, also satisfies the continuity equation throughout the flow. The velocity components, the temperature distribution, and linear interpolation for the pressure distribution in accordance with their utmost derivative orders in the differential equations (1)-(4) are as follows:

$$
U(X, Y)=N_{\beta} U_{\beta}, V(X, Y)=N_{\beta} V_{\beta}, \theta(X, Y)=N_{\beta} \theta_{\beta}, P(X, Y)=H_{\lambda} P_{\lambda}
$$

where $\beta=1,2, \ldots \ldots, 6 ; \lambda=1,2,3$.

Substituting the element velocity component distributions, the temperature distribution, and the pressure distribution from equations (1)-(4), the finite element equations can be written in the form:

$$
\begin{aligned}
& K_{\alpha \beta^{x}} U_{\beta}+K_{\alpha \beta^{y}} V_{\beta}=0 \\
& K_{\alpha \beta \gamma^{x}} U_{\beta} U_{\gamma}+K_{\alpha \beta \gamma} V_{\gamma} U_{\gamma}+M_{\alpha \mu^{x}} P_{\mu}+\frac{1}{\operatorname{Re}}\left(S_{\alpha \beta^{x x}}+S_{\alpha \beta}{ }_{\alpha y}\right) U_{\beta}=Q_{\alpha} \\
& K_{\alpha \beta \gamma^{x}} U_{\beta} V_{\gamma}+K_{\alpha \beta \gamma^{y}} V_{\gamma} V_{\gamma}+M_{\alpha \mu^{y}} P_{\mu}+\frac{1}{\operatorname{Re}}\left(S_{\alpha \beta^{x x}}+S_{\alpha \beta^{y y}}\right) V_{\beta}-\operatorname{Ra} \operatorname{Pr} K_{\alpha \beta} \theta_{\beta}=Q_{\alpha^{v}} \\
& K_{\alpha \beta \gamma} U_{\beta} \theta_{\gamma}+K_{\alpha \beta \gamma}{ }^{y} V_{\beta} \theta_{\gamma}+\frac{1}{\operatorname{Re.Pr}}\left(S_{\alpha \beta^{x x}}+S_{\alpha \beta}{ }_{\alpha y}\right) \theta_{\beta}=Q_{\alpha} \theta
\end{aligned}
$$

where the coefficients in element matrices are in the form of the integrals over the element area and along the element edges $S_{0}$ and $S_{w}$ as,

$$
K_{\alpha \beta^{x}}=\int_{A} N_{\alpha} N_{\beta, x} d A, K_{\alpha \beta^{y}}=\int_{A} N_{\alpha} N_{\beta, y} d A, K_{\alpha \beta \gamma^{x}}=\int_{A} N_{\alpha} N_{\beta} N_{\gamma, x} d A,
$$




$$
\begin{aligned}
& K_{\alpha \beta \gamma}^{y}=\int_{A} N_{\alpha} N_{\beta} N_{\gamma, y} d A, K_{\alpha \beta}=\int_{A} N_{\alpha} N_{\beta} d A, S_{\alpha \beta^{x x}}=\int_{A} N_{\alpha, x} N_{\beta, x} d A, \\
& S_{\alpha \beta}^{y y}=\int_{A} N_{\alpha, y} N_{\beta, y} d A, M_{\alpha \mu^{x}}=\int_{A} H_{\alpha} H_{\mu, x} d A, M_{\alpha \mu} y=\int_{A} H_{\alpha} H_{\mu, y} d A, \\
& Q_{\alpha} u=\int_{S_{0}} N_{\alpha} S_{x} d S_{0}, Q_{\alpha}{ }=\int_{S_{0}} N_{\alpha} S_{y} d S_{0}, Q_{\alpha} \theta=\int_{S_{w}} N_{\alpha} q_{1_{w}} d S_{w}, \\
& Q_{\alpha} \theta=\int_{S_{w}} N_{\alpha} q_{2_{w}} d S_{w}
\end{aligned}
$$

The set of non-linear algebraic equations (6) - (9) are shifted into linear equations by using Newton-Raphson method and reduced integration technique of Zeinkiewicz [22] and then Triangular Factorization method is used to solve these linear equations. The convergence of solutions is assumed when the relative error for each variable between consecutive iterations is put aside below the convergence criterion such that $\left|\Psi^{n+1}-\Psi^{n}\right|<10^{-8}$, where $\mathrm{n}$ is the current number of iteration and $\Psi=U, V, \theta$.

\section{Grid Sensitivity Test}

The field variables grid independency solutions have been inspected by the groundwork results. Test for the accurateness of grid fineness is carried out to find the finest grid number.A grid modification study is performed for a triangular cavity with $\operatorname{Pr}=0.71, \operatorname{Re}=100$ and $R a=10^{4}$ to obtain grid independent result.It is observed that grid independence is achieved for 23053 nodes and 3490 elements to get accurate result where there is petty change in $\mathrm{Nu}$ with further increase of mesh elements (Table 1). Figure 2(a) also shows the test of grid sensitivity of the Nusselt number $(\mathrm{Nu})$ vs element number. Besides current mesh structure of elements for triangular enclosures is shown in Figure 2(b).

Table 1: Grid sensitivity test at $\operatorname{Pr}=0.71, \operatorname{Re}=100$ and $\operatorname{Ra}=10^{4}$

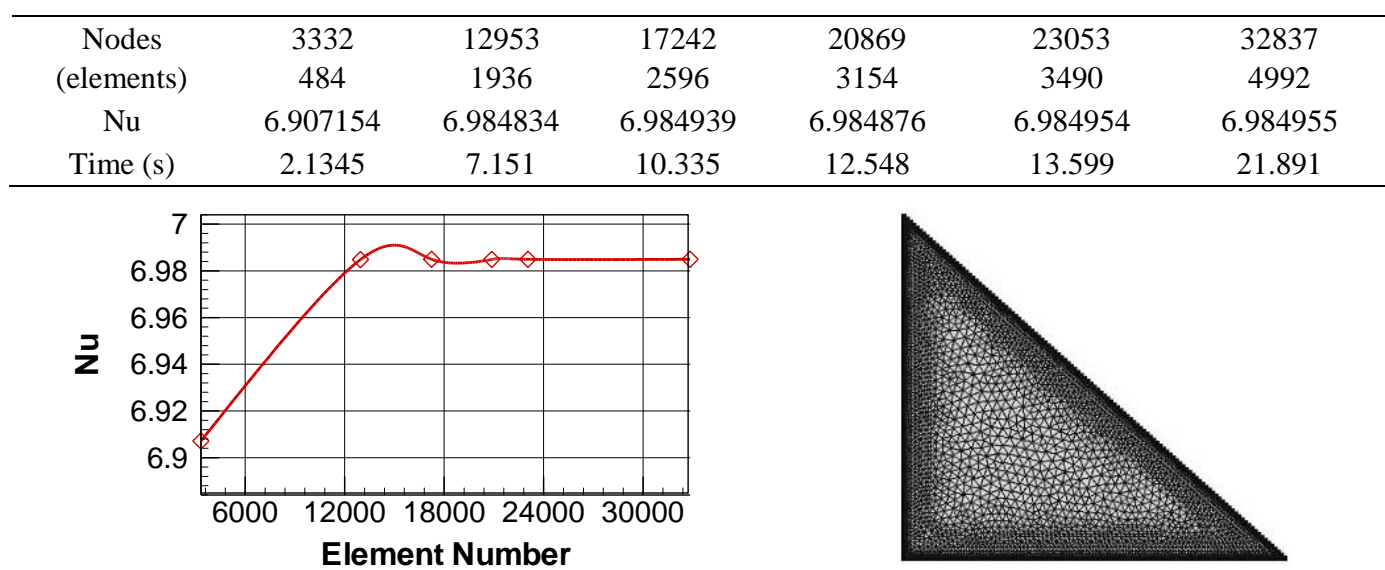

Fig. 2(a): Grid sensitivity test

Fig. 2(b) : Current Mesh Structure 


\section{Code Validation}

In order to validate the code, the present numerical code is verified against a documented numerical study. Here, the numerical calculation with $\operatorname{Ra}=2 \times 10^{4}$ and $\operatorname{Pr}=0.71$ in a triangular cavity is solved for pure natural convection and the results are compared with those reported by Basak et al. [3], demonstrate that, the numerical solutions (present work and Basak et al. [3]) are in good agreement.
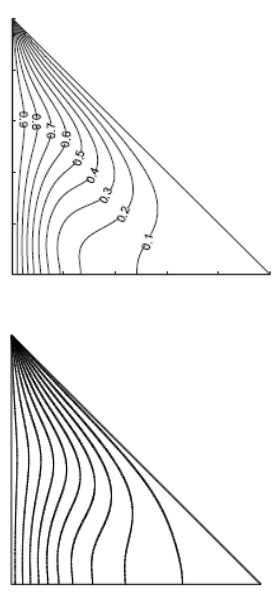

Isotherm

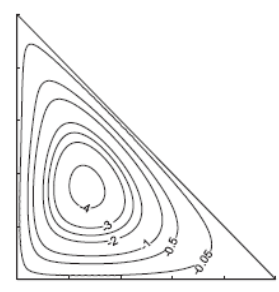

Basak et al. [3]

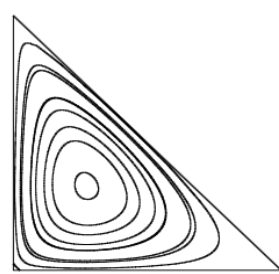

Streamline

Fig. 3: Comparison of the results for the steady surface temperature with Basak et.al. [3] and present work for $R a=2 \times 10^{4}$ and $\operatorname{Pr}=0.71$.

\section{Results and Discussion}

In this paper, two dimensional steady mixed convection for heat flow in a lid driven triangular enclosure with uniformly heated bottom wall, cold temperature of vertical wall and inclined insulated wall has been studied. Numerical results are presented in order to conclude the properties of the presence of dimensionless parameters, for example, Rayleigh number $(R a)$, Reynolds number $(R e)$, Prandtl number $(P r)$ in the cavity. Since, an analysis of all combinations of these parameters is not applied; hence, many basic dimensionless parameters are required to characterize a system. To explain the effects of several parameters at a small fraction of the possible situations, numerical results will be aimed. Results are obtained for a wide range of parameters such as, for Rayleigh number from $10^{3}$ to $10^{4}$ and Reynolds number from 40 to 110 . The results for parameter also show the consistent performance of the present numerical appearance to obtain stream function and isotherm profiles.

The effects of Reynolds number $\operatorname{Re}(=40,50,70,100$ and 110$)$ at three values of $\operatorname{Ra}\left(=10^{3}\right.$, $5 \times 10^{3}$ and $10^{4}$ ) in terms of isotherms and streamlines for the liquid flow patterns inside the 
enclosure has been represented in the figures (4-8) asthe Prandtl number $(P r)$ is kept fixed at 0.71 . By the aid of stream function's definition, the streamlines correspond to anticlockwise circulation for ' $+\psi$ ' and those with clockwise circulation for ' $-\psi$ '. It is seen that the fluid flow rises up along the side of cold vertical wall and flow goes down along the right inclined wall which corresponds a rotation within the enclosure for three values of $R a$ at $R e=40$ for upward motion of left vertical wall. If $R a$ changes then the orientation of the core in the recirculation cell also changes.

Next, for all values of $R a$,secondary rotating cells are developed in the enclosure, which indicates, both the conducting force and buoyancy force are present in the enclosure, while $R e=50$ is fixed. However, as $R a$ increases the value of $\psi$ and the cells in the enclosure become larger in size. It is also seen from figures 4 - 8 that, at different $R a$ and $R e=110$, the value of $\psi$ of the rotating cell raises sharply and also more tautened to the adjacent boundary wall.

At present, the Reynolds number'supshot on the temperature distribution in the enclosure is the main attention to us. From the left columns of figures $4-8$, it can be observed that isothermal lines are nearly similar to the uniform heating of bottom walls, which is the same as conduction-like distribution. Thisis also perceived that isothermal lines begin to turn back from the cold wall toward the uniform heating wall near the bottom wall owing to the dominating influence of conduction and forced convection in the lower part of the enclosure for all cases. Besides, at the higher values of $R a$, more important distortion in isothermal lines near to the left bottom corner of the enclosure is observed. It is seen that the isotherm patterns replicates a conductive pattern of energy transfer at the lower values of Reynolds number $R e(R e=40,50,70)$ and a convective pattern of energy transfer at the higher values of Reynolds number $(R e=100,110)$.Last of all, the convective deformation in the isotherms develop into more at $R a=10^{4}$ and because of the strong influence of the convective current, the thermal boundary layer near the cold wall becomes more concentrated with further increasing the values of Reynolds number $(R e)$.

The variation of heat transfer rate, that is, average Nusselt number $\left(N u_{a v}\right)$ at the uniformly heated bottom wall and also the average bulk temperature $\left(\theta_{a v}\right)$ in the enclosure are displayed as a function of Rayleigh number at some particular Reynolds number in figure 9(a) \& 9(b) for the abovementioned enclosure. It is observed that the average Nusselt number at the uniformly heated bottom wall increases considerably in the forced convection dominated region and increases very harshly in the free convection dominated region with increasing $R a$ for the higher values of Reynolds number $\operatorname{Re}(=100$ and 110$)$. However, utmost values of $N u$ is found for the uppermost value of $\operatorname{Re}(=110)$. Conversely, the average fluid temperature $\left(\theta_{a v}\right)$ in the enclosure enhances gradually for higher values of $\operatorname{Re}(=100$ and 110$)$ and but all of a sudden drop dramatically for the all value of $R e$ with increasing $R a$.

Finally, the quantitative differences of the values of $N u_{a v}$ for uniform heating of bottom wall at different values of $R e$ are indicated in Tables 2 and 3. 
Table 2: Average Nusselt numbers for uniform heating of bottom wall for different Reynolds number while $\mathrm{Re}=40,50,70,100$ and 110 and $\operatorname{Pr}=0.71$.

\begin{tabular}{|c|c|c|c|}
\hline \multicolumn{5}{|c|}{ Average Nusselt number $\left(N u_{\mathrm{av}}\right)$} \\
\hline$R e$ & $R a=10^{3}$ & $R a=5 \times 10^{3}$ & $R a=10^{4}$ \\
\hline 40 & 2.161371 & 2.555622 & 2.932312 \\
\hline 50 & 2.238306 & 2.663582 & 3.055503 \\
\hline 70 & 2.387555 & 2.375655 & 3.225533 \\
\hline 100 & 2.57956 & 3.001323 & 3.492477 \\
\hline 110 & 2.812795 & 3.330152 & 3.650401 \\
\hline
\end{tabular}

Table 3: Average bulk temperature for uniform heating of bottom wall for different Reynolds number while $\operatorname{Re}=40,50,70,100$ and 110 and $\operatorname{Pr}=0.71$.

\begin{tabular}{|c|c|c|c|}
\hline \multicolumn{4}{|c|}{ Average bulk temperature $\left(\theta_{\text {av }}\right)$} \\
\hline$R e$ & $R a=10^{3}$ & $R a=5 \times 10^{3}$ & $R a=10^{4}$ \\
\hline 40 & 0.458107 & 0.575141 & 0.301101 \\
\hline 50 & 0.461578 & 0.574775 & 0.301528 \\
\hline 70 & 0.476513 & 0.573889 & 0.301989 \\
\hline 100 & 0.484453 & 0.572426 & 0.302333 \\
\hline 110 & 0.495433 & 0.571242 & 0.318985 \\
\hline
\end{tabular}
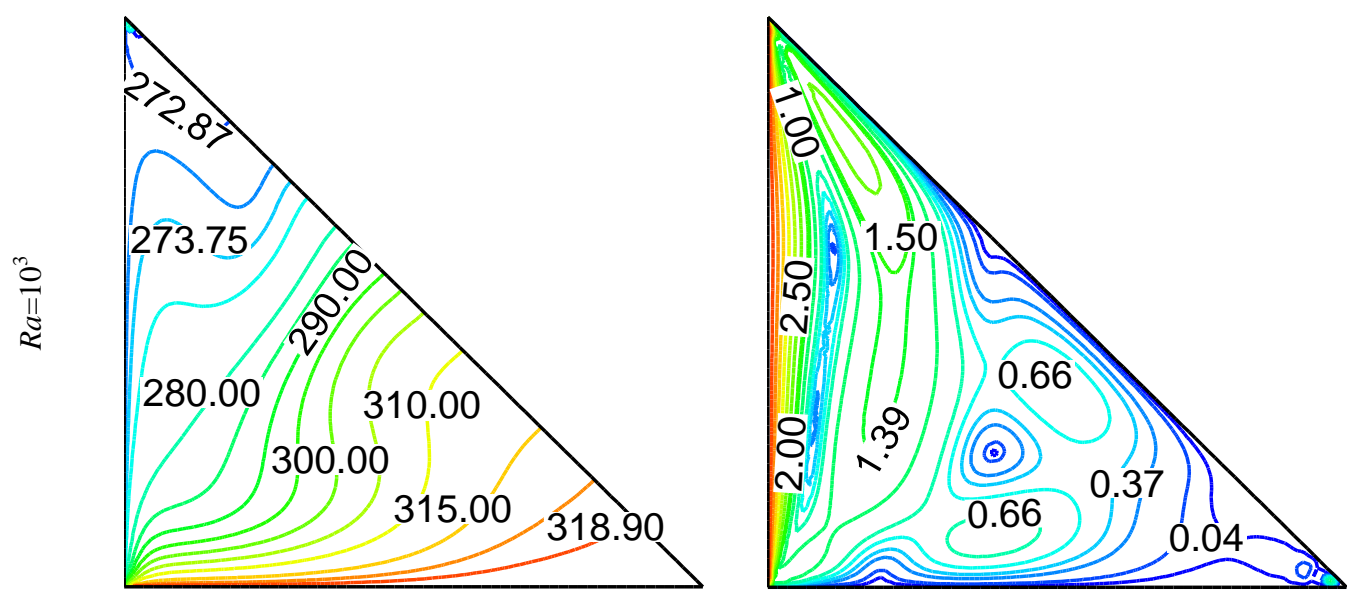

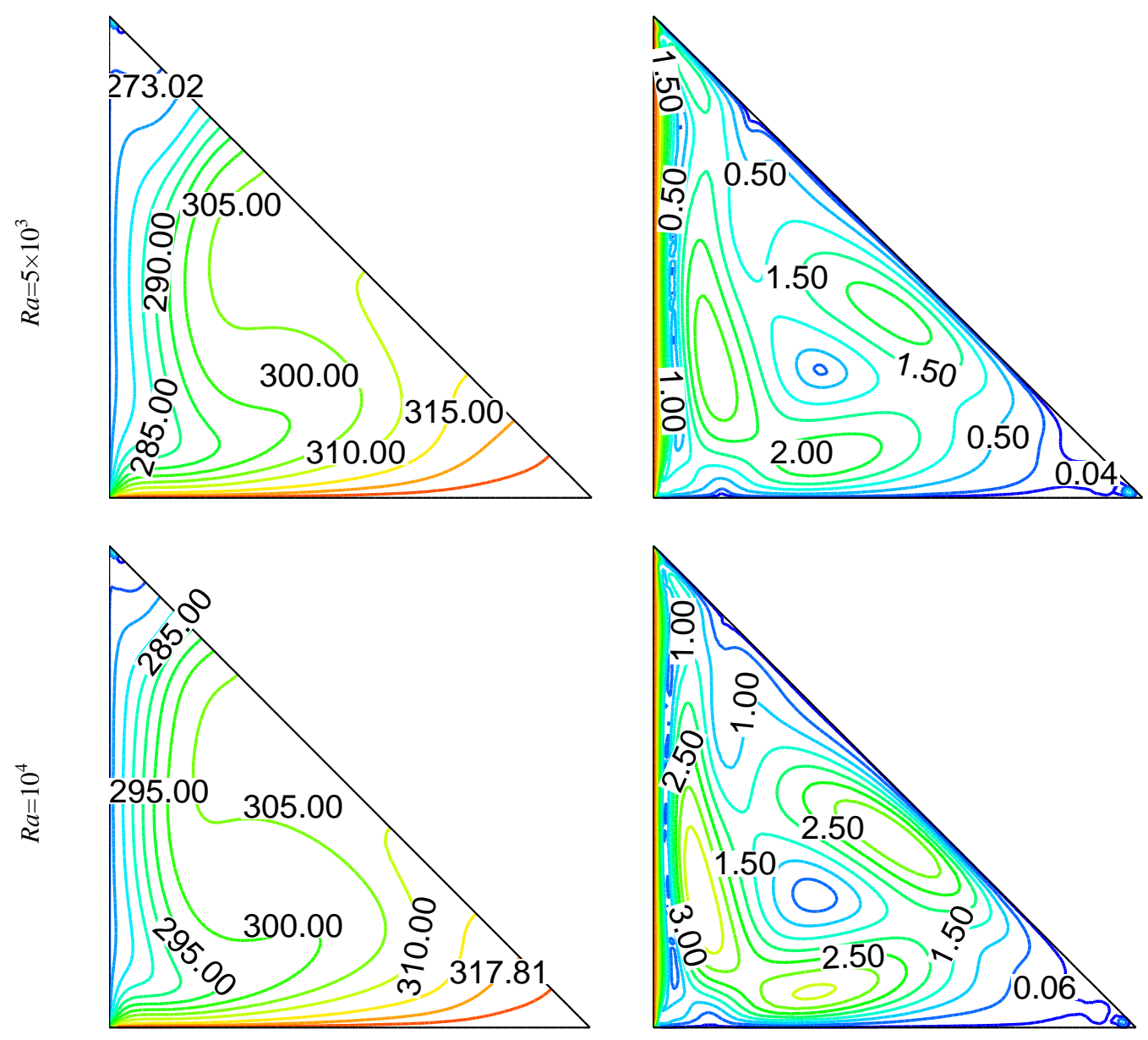

Isotherm

Streamline

Fig. 4: Isotherms and streamlines for different $R a$ with $R e=40$ and $P r=0.71$
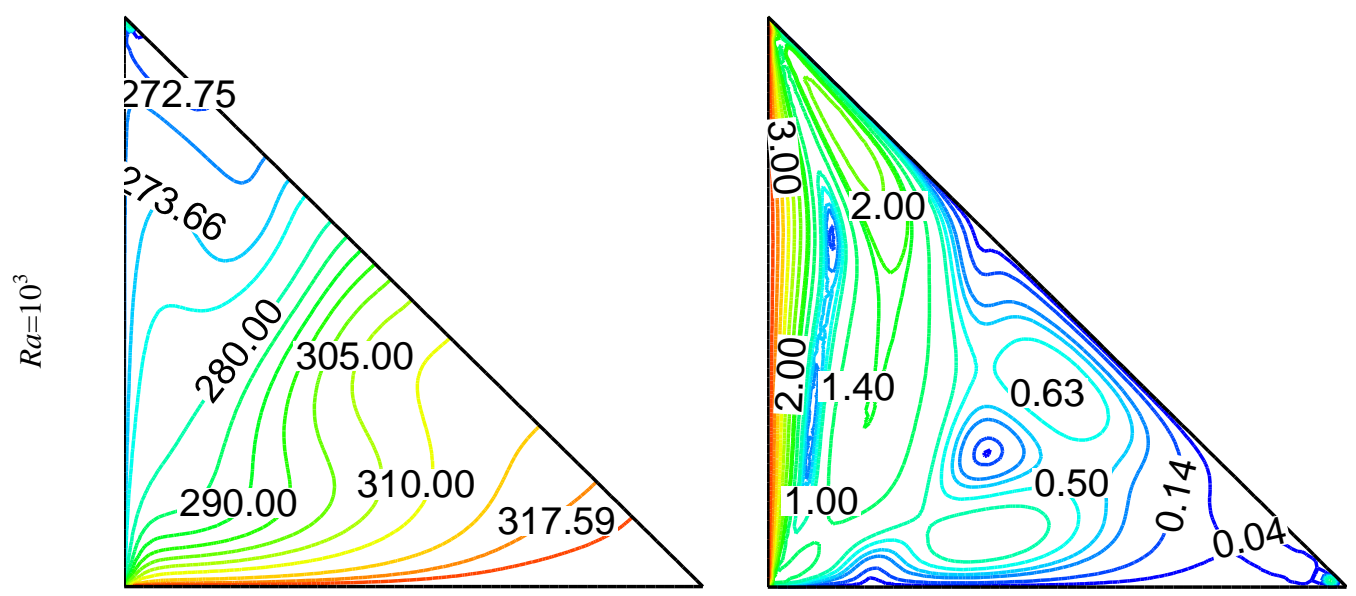

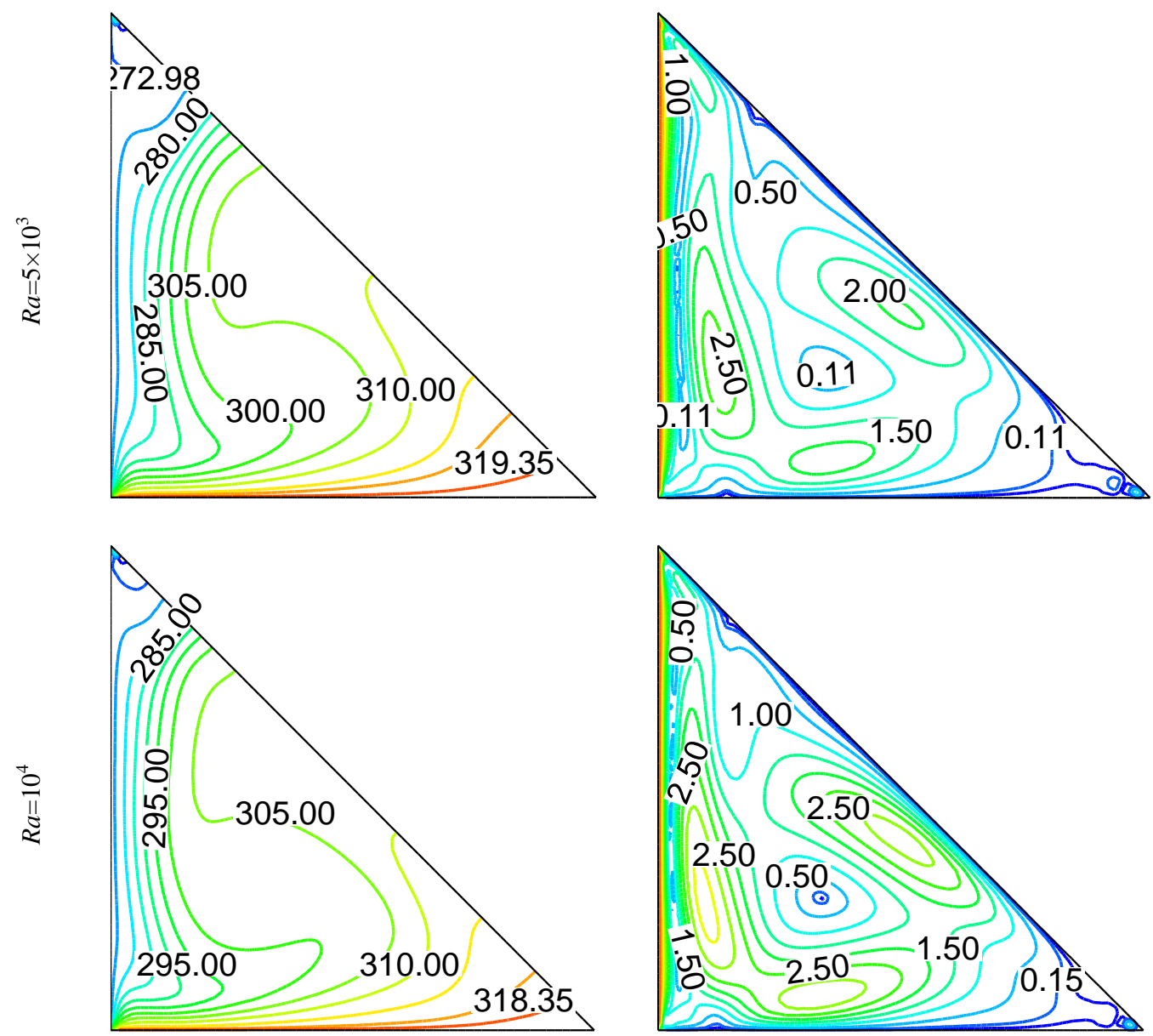

Isotherm

Streamline

Fig. 5: Isotherms and streamlines for different $R a$ with $R e=50$ and $P r=0.71$
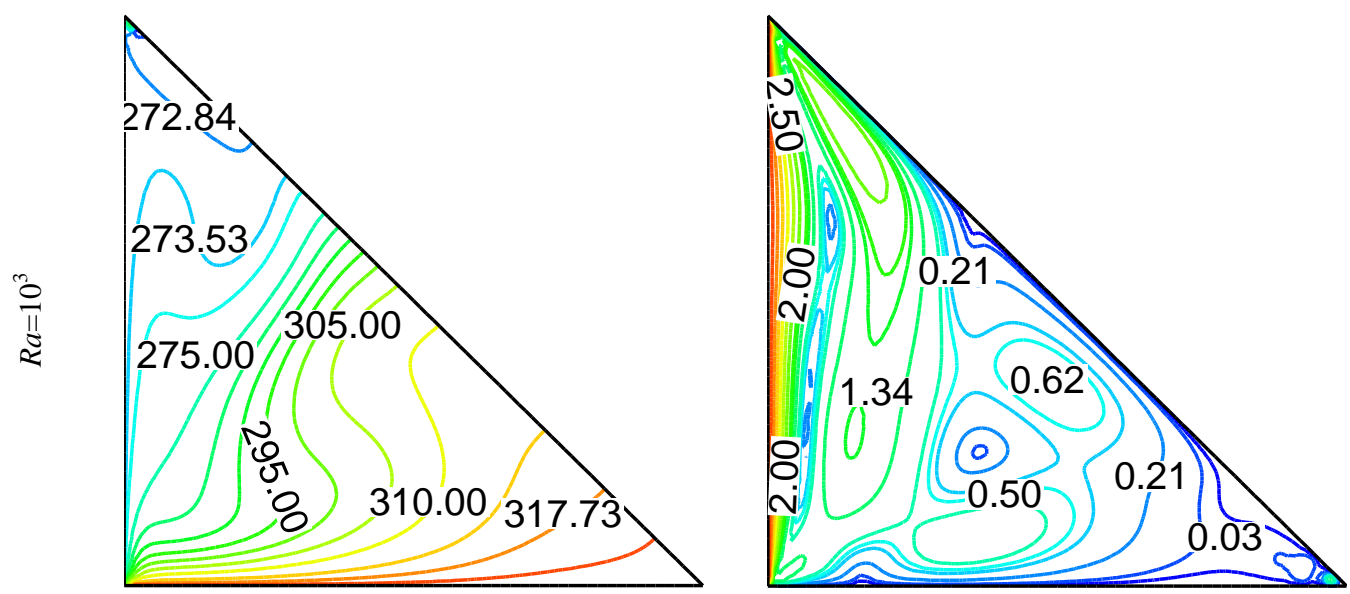

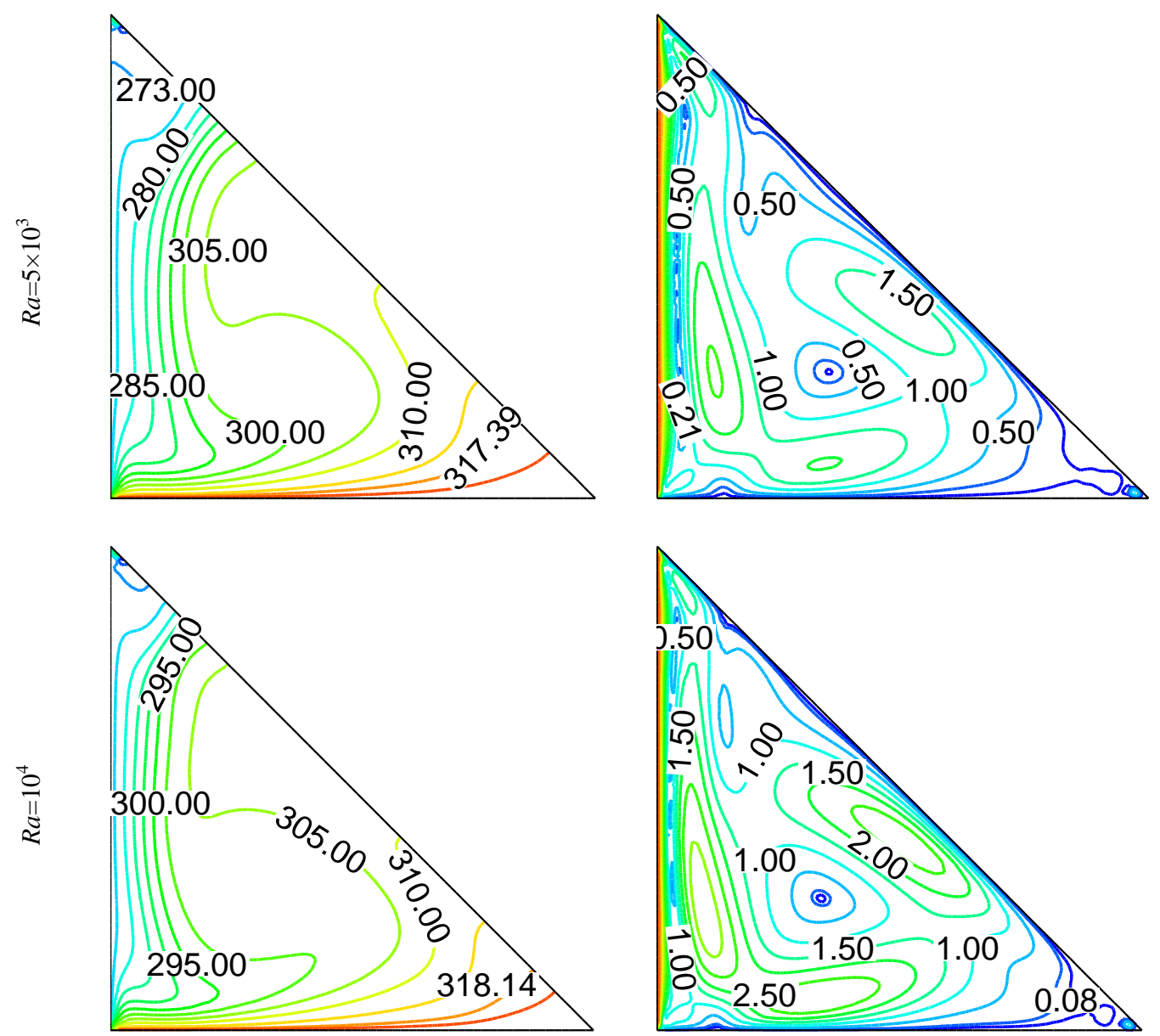

Isotherm

Streamline

Fig. 6: Isotherms and streamlines for different $R a$ with $R e=70$ and $P r=0.71$
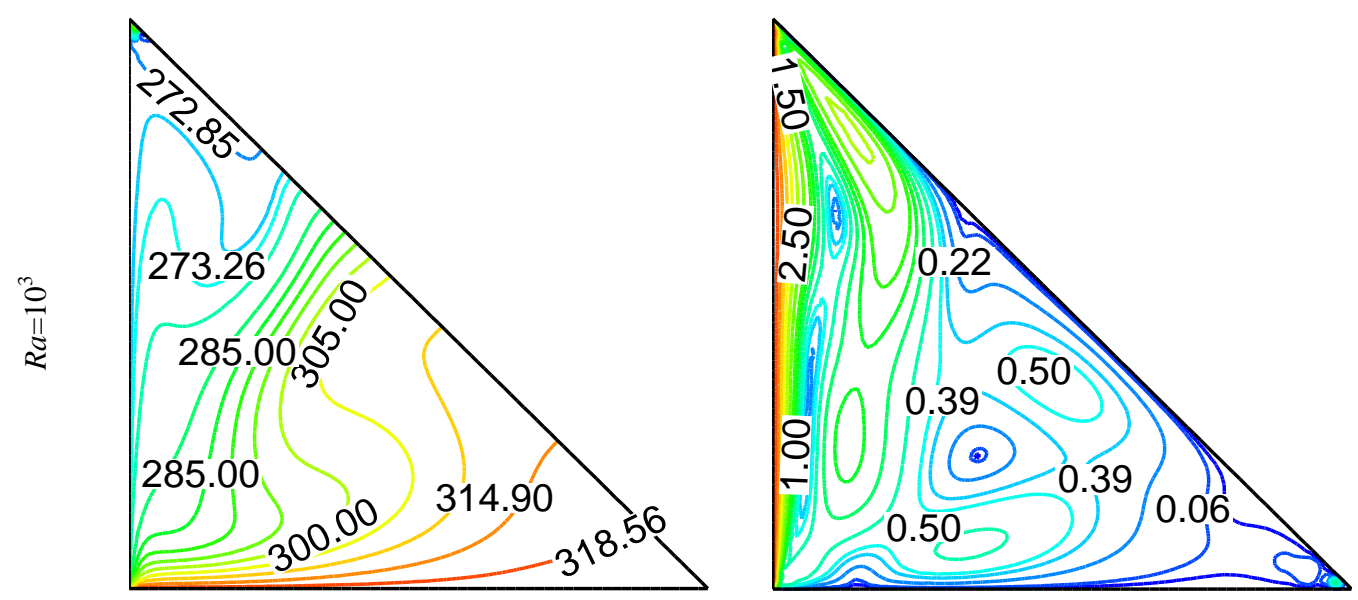

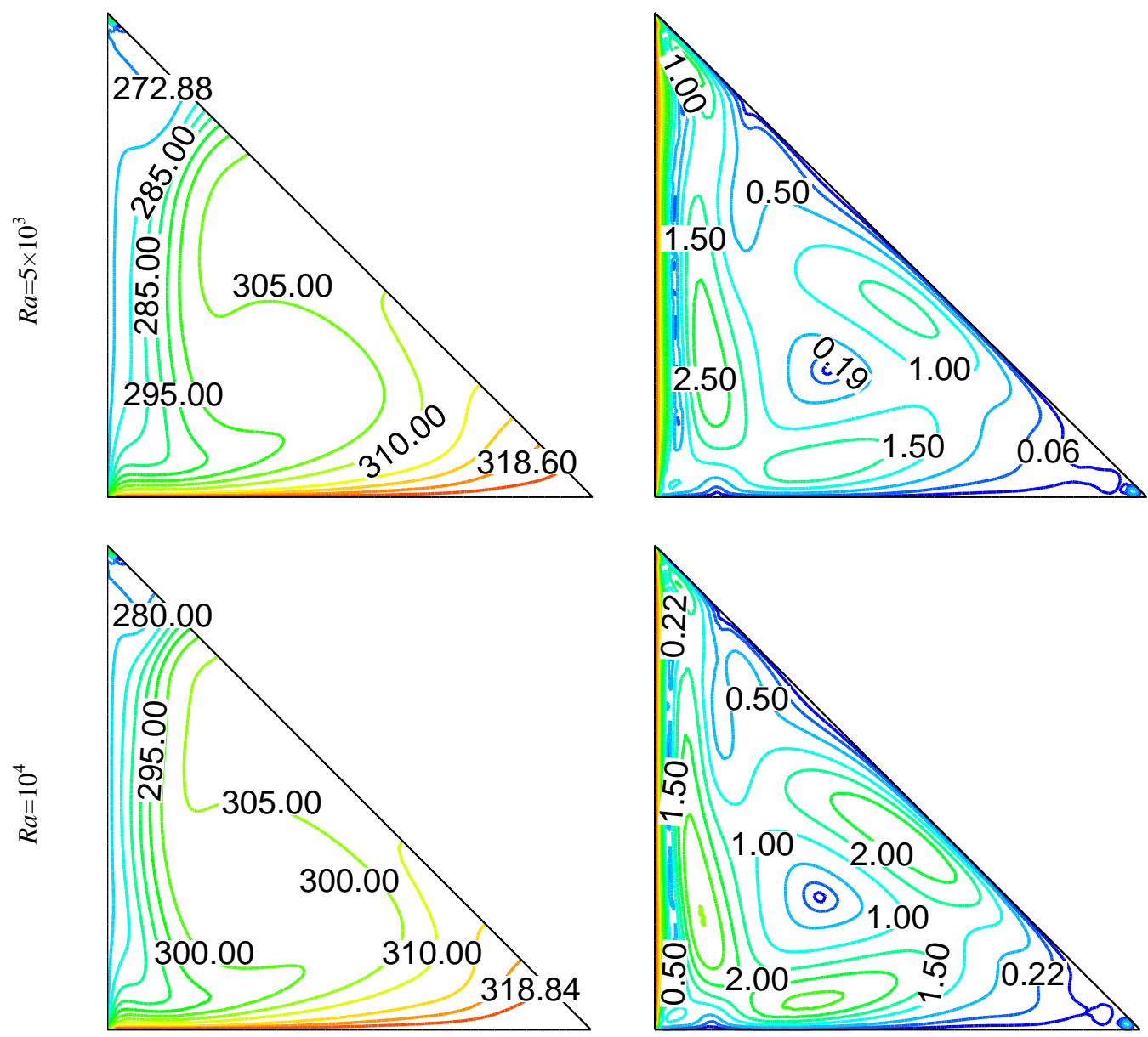

Isotherm

Streamline

Fig. 7: Isotherms and streamlines for different $R a$ with $R e=100$ and $P r=0.71$
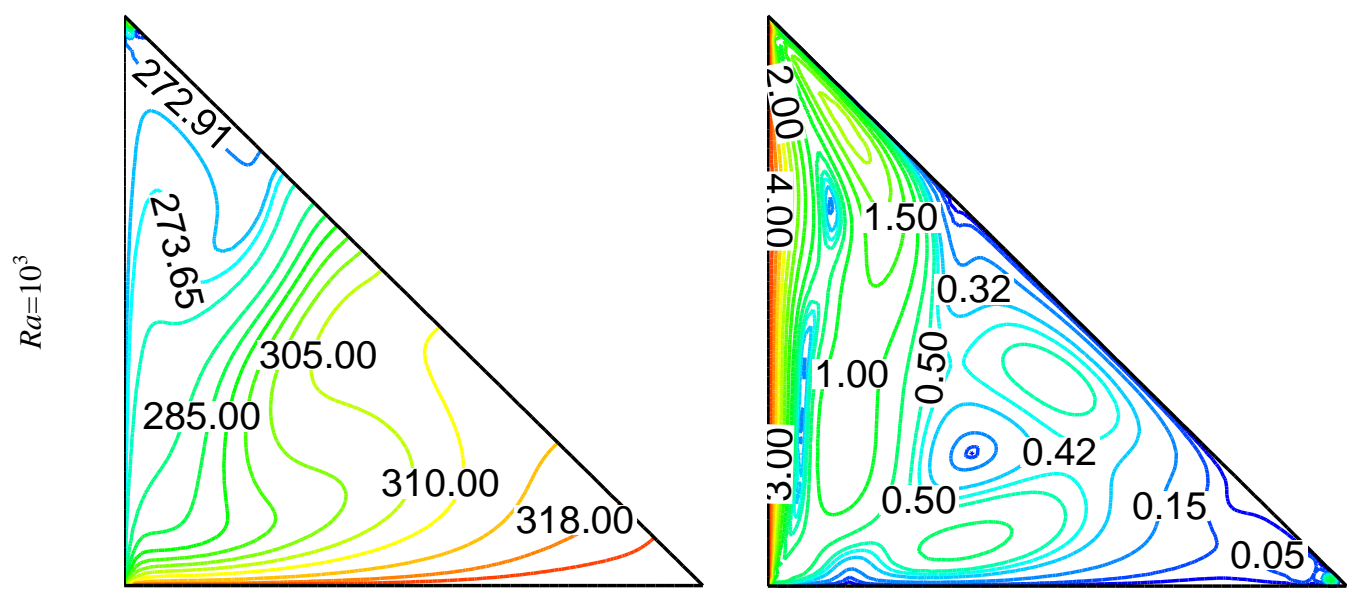

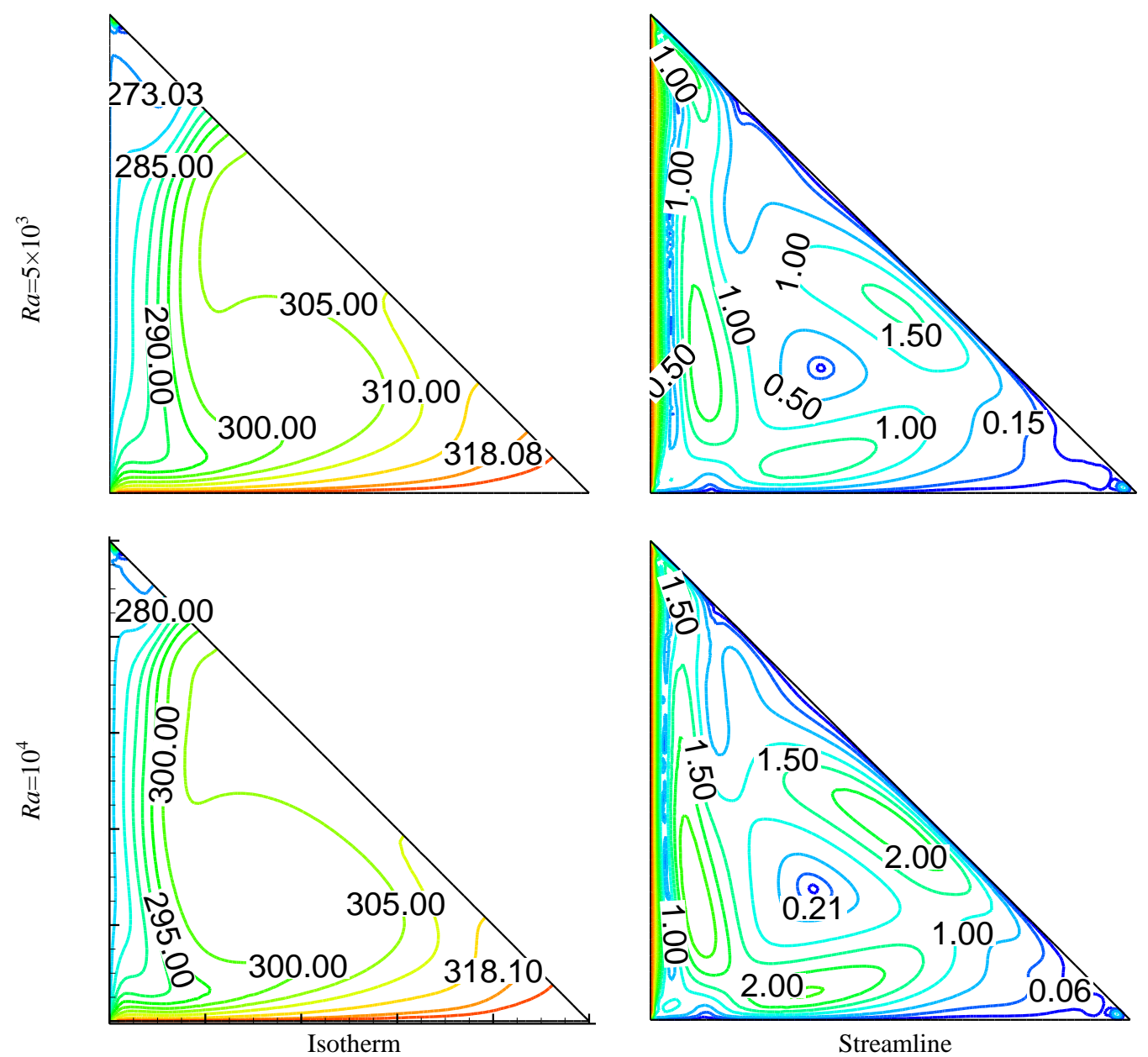

Fig. 8: Isotherms and streamlines for different $R a$ with $R e=110$ and $P r=0.71$

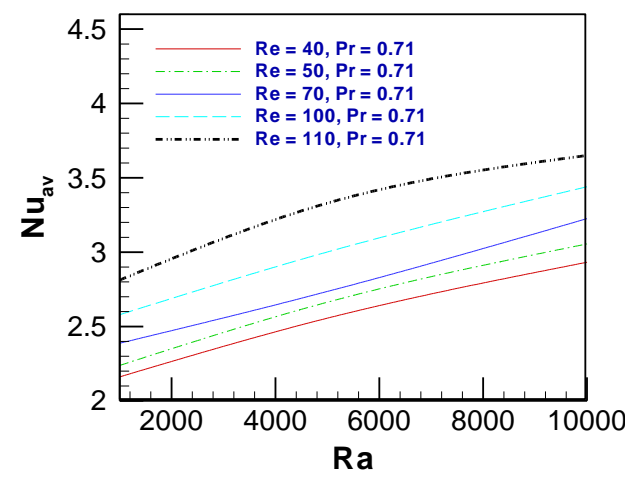

(a)

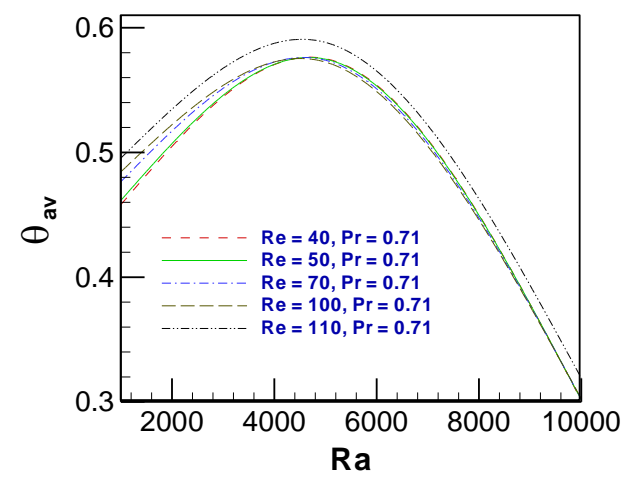

(b)

Fig. 9: Variations of $R a$ on (a) average Nusselt number and (b) average Bulk temperature when $40<R e<$ 110 and $\operatorname{Pr}=0.71$. 


\section{Conclusions}

Heat transfer via heat flow on mixed convection confined by a triangular cavity under laminar regime is inspected by using finite element method. A featured analysis of the specification of streamlines, isotherms, average Nusselt numbers at the heated surface and average bulk temperature in the triangular enclosure have been carried out for finding the effect of the dimensionless parameters. The investigation is completed for a number of relevant dimensionless groups, namely Rayleigh number $R a$ and Reynolds number $R e$. The numerical experiment reveals anassessment of heat transfer and fluid flow phenomena, which gives the following conclusions:

The numerical solutions point out that the increasing values of $R e$ gives higher heat transfer rate from the heat resource but the average bulk temperature of other side declines significantly. This means that Interesting behavior of the thermal fields and heat flow varying Reynolds number is observed.

The magnitude of the stream function's cells become larger in size and more attached to the boundary wall which is found for different values of $R a$.

The Reynolds number has also foremostresult on the heat flow and thermal distributions in the triangular enclosure. The average Nusselt number $\left(N u_{a v}\right)$ at the uniform heating of bottom wall is the highest for the $R e=110$ when Rayleigh number $10^{4}$, while the lowermost heat transfer rate for $R e=40$ when Rayleigh number $10^{3}$. As the Reynolds number shows forced convection, so for bigger value of Reynolds number buoyancy force raises inside the cavity and increases the heat transfer rate quickly.

Also, for $R e=40$ and $R a=5 \times 10^{3}$, the average bulk temperature become highestand smallest for $R a=10^{4}$.It is observed that average bulk temperature demonstrations counter behavior with average Nusselt number for Reynolds number.

\section{Acknowledgements}

Authors would like to express their gratitude to the Department of Arts and Sciences, Ahsanullah University of Science and Technology (AUST), Dhaka, Bangladeshfor providing computing facilities during this work.

\section{Nomenclature}

$C_{p} \quad$ Specific heat at constant pressure $(\mathrm{J} / \mathrm{kg} \mathrm{K})$

V Dimensionless vertical velocity

$g \quad$ Gravitational acceleration $\left(\mathrm{m} / \mathrm{s}^{2}\right)$

Gr Grashof number

$k$ Thermal conductivity of fluid(W/m K)

$v \quad$ Velocity in y-direction $\left(\mathrm{m} / \mathrm{s}^{2}\right)$

$V_{0} \quad \operatorname{Lid} \operatorname{Velocity}(\mathrm{m} / \mathrm{s})$

$K$ Thermal conductivity ratio fluid

$N$ non-dimensional distance

$x, y$ Cartesianacoordinaste $(\mathrm{m})$

$N u_{a v}$ Average Nusselt number

$X, Y$ Dimensionless Cartesian coordinates

Greek symbols

$\beta$ Coefficient of thermal expansion $\left(\mathrm{K}^{-1}\right)$ 


\author{
$\theta_{a v} \quad$ Average Bulk temperature \\ $P \quad$ Non-dimensional pressure \\ $p \quad$ Dimensional Pressure $\left(\mathrm{Nm}^{-2}\right)$ \\ $\mathrm{Pr}$ Prandtl number \\ $R a$ Rayleigh number \\ Re Reynolds number \\ $T \quad$ Dimensional temperature $(\mathrm{K})$ \\ $T_{h} \quad$ Uniformly heated temperature (K) \\ $T_{c} \quad$ Cold temperature (K) \\ $U$ Dimensionless horizontal velocity \\ $U$ Velocity in x-direction $(\mathrm{m} / \mathrm{s})$
}

$\rho$ Density of the fluid $\left(\mathrm{kg} / \mathrm{m}^{3}\right)$

$\alpha$ Thermal diffusivity $\left(\mathrm{m}^{2} / \mathrm{s}\right)$

$\Delta \theta$ Temperature difference (K)

$\theta$ Dimensionless temperature

$\mu \quad$ Dynamic viscosity of the fluid ( $\mathrm{Pa} \mathrm{s})$

$v$ Kinematic viscosity of the fluid $\left(\mathrm{m}^{2} / \mathrm{s}\right)$

$\sigma \quad$ Fluid electrical conductivity $\left(\Omega^{-1} \mathrm{~m}^{-1}\right)$

\section{REFERENCES}

[1] Akinsete, V.A., Coleman, T.A., "Heat transfer by steady laminar free convection in triangular enclosures", International Journal of Heat and Mass Transfer, 25(1982), 991-998.

[2] Asan H., Namli L., "Laminar natural convection in a pitched roof of triangular cross-section: summer day boundary conditions", Energy Buildings, 33 (2000), 69-73.

[3] Basak T., Roy S., Thirumalesha Ch., "Finite element analysis of natural convection in a triangular enclosure: Effects of various thermal boundary conditions", Chemical Engineering Science, 62(9), (2007), 2623-2640.

[4] Basak, T., Aravind, G., Roy, S., Balakrishnan, A.R., "Heatline analysis of heat recovery and thermal transport in materials confined within triangular cavities" International Journal of Heat and Mass Transfer, 53 (2010), 3615-3628.

[5] Basak, T., Roy, S., Balakrishnan, A.R., "Effects of thermal boundary conditions on natural convection flows within a square cavity", International Journal of Heat and Mass Transfer, 49 (23-24), (2006), 4525-4535.

[6] Biswas, G., Laschefski, H., Mitra, N. K. and Fiebig, M., "Numerical investigation of mixed convection heat transfer in a horizontal channel with a built in square cylinder", Numer. Heat Transfer, 18(1990), 173-188.

[7] Taylor C. and Hood P., Computer and Fluids 1(1), (1973), 73-100.

[8] Das D., Lukose L., Basak T., "Role of multiple discrete heaters to minimize entropy generation during natural convection in fluid filled square and triangular enclosures", International Journal of Heat and Mass Transfer, Part A, 127(2018), 1290-1312.

[9] Das D., Basak T., "Role of discrete heating on the efficient thermal management within porous square and triangular enclosures via heatline approach", International Journal of Heat and Mass Transfer, 112 (2017), pp. 489-508.

[10] Hossain, M. A., and Gorla, R. S. R., "Effect of viscous dissipation on mixed convection flow of water near its density maximum in a rectangular enclosure with isothermal wall”, Int. J. of Numer. Methods for Heat and Fluid Flow, Vol. 16(1), (2006), 5-17.

[11] Karyakin, YU.E, Sokovishin, YU. A., "Transient natural convection in triangular enclosures", International Journal of Heat and Mass Transfer, 31(1988), 1759-1766.

[12] Kaushik, S.C., Kumar, R., Garg, H.P., Prakash, J., "Transient analysis of a triangular built-in-storage solar water-heater under winter conditions", Heat Recovery Systems and CHP, 14 (4), (1994), 337-341.

[13] Li., M., and Tang, T., "Steady viscous flow in a triangular cavity by efficient numerical techniques", Comput. Math. Appl., 31(1996), 55-65. 
[14] Luo, W. J., and Yang, R. J., "Multiple fluid flow and heat transfer solutions in a two-sided lid-driven cavity", Int. J. of Heat and Mass Transfer, 50(2007), 2394-2405.

[15] Dechaumphai P., Finite Element Method in Engineering, 2nd ed. (Chulalongkorn University Press), Bangkok, 1999.

[16] Papanicolaou, E., and Jaluria, Y., "Mixed convection from an isolated heat source in a rectangular enclosure", Numer. Heat Transfer, Part A, 18 (1990), 427-461.

[17] Papanicolaou, E., and Jaluria, Y., "Transition to a periodic regime in mixed convection in a square cavity”, J. Fluid Mech., 239 (1992), 489-509.

[18] Rahman M.M., Alim M.A., Mamun M.A.H., Chowdhury M.K. and lslam A.K.M.S "Numerical Study of Opposing Mixed Convection in a Vented Enclosure" ARPN J. of Eng. and Applied Sci., 2 (2007), 25-36.

[19] Saha S. C., Khan M.M.K., Gu Y.T., "Unsteady buoyancy driven flows and heat transfer through coupled thermal boundary layers in a partitioned triangular enclosure", International Journal of Heat and Mass Transfer, 68 (2014), 375-382.

[20] Sheremet M. A., Pop I., Anuar Ishak A., "Time-dependent natural convection of micropolar fluid in a wavy triangular cavity”, International Journal of Heat and Mass Transfer, 105 (2017), 610-622.

[21] Varol Y., Oztop H.F., Varol A., "Free convection in porous media filled right-angle triangular enclosures", Int. Commun. Heat Mass Transfer, 33 (2006), 1190-1197.

[22] Zeinkiewicz O.C., Taylor R.L., Too J.M., Reduced integration technique in general analysis of plates and shells, Int. J. Numer. Methods Eng. 3 (1971) 275-290. 